\title{
O ESTADO DA ARTE SOBRE A FORMAÇÃO DO ENFERMEIRO PARA A GESTÃO EM SAÚDE
}

\author{
THE ART STATE UPON THE NURSE FORMATION \\ TOWARDS HEALTHCARE MANAGEMENT
}

\author{
ESTADO DEL ARTE EN LA FORMACIÓN \\ DEENFERMERAS PARA LA GESTIÓN DE LA SALUD
}

\begin{abstract}
Natália Paranhos de Araújo*, Talita Oliveira da Silva Miranda*, Carolina Pedroza de Carvalho Garcia**
\end{abstract}

\begin{abstract}
Autor correspondente: Natália Paranhos de Araújo - nati_paranhos@hotmail.com
*Graduanda do curso de enfermagem da Escola Bahiana de Medicina e Saúde Pública, **Enfermeira, Professora Mestra em Enfermagem da Escola Bahiana de Medicina e Saúde Pública.
\end{abstract}

\section{RESUMO}

O enfermeiro se destaca no contexto gerencial, nos diversos serviços e níveis de atenção à saúde. Porém, surge como dúvida, se esses profissionais estão sendo formados com as competências necessárias para ocupar estes cenários, se fazendo necessário repensar uma formação capaz de sustentar uma prática profissional qualificada para o trabalho de gestão em saúde. O estudo tem como objetivo identificar a produção literária acerca da formação do enfermeiro para a gestão em saúde. Trata-se, portanto, de uma revisão bibliográfica narrativa, com coleta de dados de artigos publicados na língua portuguesa, entre os anos de 2000 a 2013, nas bases de dados SCIELO, LILACS, MEDLINE e Biblioteca digital de tese e dissertações da USP, relacionadas com o tema desta pesquisa e disponíveis gratuitamente, na íntegra, em formato eletrônico. Foram encontradas 466 publicações, sendo selecionados 68 artigos, destes, foram incluídos 35 artigos e or tese de doutorado. Do material selecionado para análise, emergiu três categorias analíticas: a formação do enfermeiro para a prática de gestão; a influência das exigências do mercado de trabalho na formação para a gestão e as competências para a formação no âmbito da gestão em saúde. Importantes avanços ocorreram, apesar de obstáculos ainda existirem, na formação do enfermeiro, que atualmente caminha para uma nova perspectiva, sendo ela ainda pouco estudada e discutida, mas dando indícios de que a velha concepção técnica assistencial do enfermeiro está sendo substituída por componentes éticos, políticos, sociais e desenvolvimento de competências.

Palavras-Chaves: Ensino; Enfermagem; Educação em enfermagem; Gestão em Saúde; e Administração de Serviços de Saúde. 


\begin{abstract}
Nurses stand out in the management context, in numerous services and levels of healthcare. However, there are doubts if these professionals are being trained with all the necessary competencies to occupy the position, making it important to rethink the capabilities of school programs, in order to sustain qualified professionals to work in health management. This study has the objective to identify the academic development of nurses for the management of healthcare. To address this issue, the research acts as a literature revision with collection of data of relevant public electronic articles written in Portuguese, between 2000 and 2013, in databases SciELO, LILACS, MEDLINE and Library Digital thesis and dissertations USP. A total of 466 publications were found, but only 68 were selected, including 35 articles and or doctor's degree exam. From all material selected to be analyzed, arose three analytical categories: the nurse academic development to practice management; the influence of the job market requirements upon the academic development; and the competences to act as healthcare managers. Important advances occur despite some obstacles for the academic development of nurses that are currently walking towards a new perspective. Although yet to be more studied and discussed, this new perspective already shows some signs that the old conception that the nurses are only assistant-technicians is being replaced with ethical, political, social and skills development.
\end{abstract}

Descriptors: Education; Nursing; Nursing Education; Health Management; Administration of Health Services.

\title{
RESUMEN
}

La enfermera se encuentra en el contexto empresarial, los distintos servicios y niveles de atención de salud. Sin embargo, parece dudar de que estos profesionales están siendo capacitados con las habilidades necesarias para tomar en estos casos, por lo que es necesario repensar una formación capaz de sostener una práctica profesional calificado para trabajar en la gestión de la salud. El estudio tiene como objetivo identificar la producción literaria en la formación de las enfermeras para la gestión de la salud. Es, por tanto, una revisión de la literatura narrativa con la recopilación de datos de artículos publicados en el idioma Inglés, entre los años 2000-2013, las bases de datos SciELO, LILACS, MEDLINE y la base de datos de la biblioteca de tesis y disertaciones digitales USP relacionada con el tema de esta investigación y de libre acceso en su totalidad en formato electrónico. Se encontraron 466 publicaciones, se seleccionaron 68 artículos, de estos, se incluyeron 35 artículos y 01 tesis doctorales. El material seleccionado para el análisis, surgieron tres categorías analíticas : la formación de las enfermeras para la gestión de la práctica; la influencia de las demandas del mercado de trabajo de gestión de la formación y las habilidades para la formación en gestión de la salud. Importantes avances se han producido a pesar de los obstáculos todavía existen, en la educación de enfermería, que se destinan actualmente a un nuevo punto de vista, es aún poco estudiado y discutido, pero dando evidencia de que el viejo asistencia en el diseño técnico de las enfermeras siendo reemplazado por componentes éticos, desarrollo político, social y habilidades.

Palabras clave: Educación; Enfermería; Educación en enfermería; Gestión de la Salud; Servicios de Administración y de la Salud. 


\section{INTRODUÇÃO}

Os saberes acerca do gerenciamento em saúde originaram-se a partir da necessidade de organizar os hospitais e foram historicamente incorporados no trabalho do enfermeiro. Porém, o entrelaçamento entre cuidar e gerenciar sempre se mostrou como um desafio, tendo sido mais enfatizado a partir da década de 1990, tanto no aspecto da formação inicial do profissional, como na atuação de lideranças de enfermagem. ${ }^{(1)}$

Essa formação da graduação no Brasil esteve, por muitas décadas, atrelada, exclusivamente, a uma visão pragmática da profissão. Revela-se então, no que tange á assistência hospitalar, que um frágil embasamento impõe aos enfermeiros dificuldades em compreender o seu papel gerencial e as razões que motivaram sua inserção no nível hospitalar. Tal formação vem contribuindo para gerar e alimentar a concepção equivocada que os enfermeiros apresentam em torno de sua própria prática profissional. $(1,2)$

Vale ressaltar, no contexto da gestão pública, que a ascensão profissional dos enfermeiros deveu-se, principalmente, com a criação do Sistema Único de Saúde - SUS e, mais precisamente, às estratégias de consolidação surgidas na década de 1990, notadamente com o Programa de Agentes Comunitários de Saúde - PACS e o Programa de Saúde da Família - PSF. Observa-se a valorização do enfermeiro pela a capacidade de gestão, sendo reconhecida em todos os níveis de gestão do SUS no âmbito municipal, estadual e federal (3).

O projeto da Reforma Sanitária Brasileira e o cuidado no SUS requeriam que a formação do enfermeiro fosse sustentada por um corpo de conhecimentos que levasse em consideração os problemas dos brasileiros em suas realidades concretas e históricas, de modo a contemplá-los nos aspectos biológico, psicológico, cultural e social. Essa formação deveria assegurar ao enfermeiro competência para a gestão do cuidado, no âmbito técnico-científico, administrativo e político. ${ }^{(3)}$
No que tange as Diretrizes Curriculares Nacionais - DCNs, que norteiam o ensino de graduação em Enfermagem, apontam para as necessidades do SUS, ao reconhecer que o enfermeiro deve ser capaz de conhecer e intervir sobre os problemas e situações de saúde-doença mais prevalentes no perfil epidemiológico nacional, com um perfil generalista, humanista, crítico-reflexivo, com rigor científico e intelectual, pautado nos princípios éticos. ${ }^{(4,5)}$

De acordo com as DCNs, o conteúdo programático do curso de graduação em enfermagem, aponta para o exercício de seis competências, onde cinco delas podem ser classificadas como competências gerenciais: tomada de decisões, comunicação, liderança, administração, gerenciamento e educação permanente. ${ }^{(6,7)}$

Dessa forma, se faz necessário pensar o ensino de enfermagem dentro de uma perspectiva de desenvolvimento de competências e habilidades que possam sustentar uma prática profissional qualificada para o trabalho de gestão em saúde. Mudando, portanto, a visão de muitos dos profissionais que comumente praticam uma ação meramente técnica assistencialista, para uma concepção mais ampla do significado do cuidar em saúde.

A palavra gerência é de origem latina genere que significa $o$ ato de gerir, administrar. A gestão, gerência ou administração, são termos que podem ser considerados sinônimos, ainda que, conjunturalmente e dependendo da situação, alguns deles se destaquem com significado mais abrangente e de maior relevância. ${ }^{(8)}$

Vale salientar a diferenciação dos conceitos utilizados preliminarmente nessa pesquisa, acerca dos termos gerência/gerenciamento e gestão. De acordo com as Normas Operacionais Básicas/96 conceitua-se gerência/gerenciamento como sendo a administração de processos em uma unidade de saúde (ambulatório, hospital, instituto, fundação, entre outras) e gestão como a atividade de dirigir um sistema de saúde (municipal, estadual ou nacional) ou uma unidade de saúde, mediante o exercício de funções de coordenação, articu- 
lação, negociação, planejamento, acompanhamento, controle, avaliação e auditoria. ${ }^{(9,10)}$

Pode-se então, entender que a gestão constitui um importante instrumento para a efetivação das políticas de saúde, pois incorpora um caráter articulador e integrativo, em que a ação de gestão é determinada e determinante no processo de organização dos serviços de saúde. ${ }^{(1)}$

O enfermeiro se destaca no contexto gerencial e de gestão de tal forma, que os próprios especialistas em administração reconhecem essa característica. ${ }^{(6)}$ As áreas de atuação dos enfermeiros são diversas, no que tange ao panorama geral de sua atuação gerencial. A ampliação desses campos de atuação deve-se ao reconhecimento do profissional enfermeiro $e$ ao seu preparo para atuar em todos os níveis de assistência à saúde. Este fato revela que o mercado de trabalho para os enfermeiros cresce a cada dia e se diversifica cada vez mais. Entretanto, surge como dúvida se os enfermeiros estão sendo formados com as competências necessárias para ocupar estes cenários. ${ }^{(4)}$

Outro possível fator que contribui para essa capacidade de gerir os diversos serviços de saúde em suas múltiplas instâncias está no aprendizado diário, dinâmico e complexo do enfermeiro em coordenar o processo de trabalho de enfermagem e da equipe multiprofissional, que historicamente está vinculado à administração/gestão de setores nas organizações de saúde, recursos humanos, gerenciamento do cuidado e líder de equipe.

Diante do exposto, evidencia-se a relevância do estudo nessa temática a fim de entender e aprofundar os questionamentos e reflexões sobre a formação desse profissional para a gestão em saúde, considerando a importância, a capacidade e o potencial que o enfermeiro apresenta, bastante requisitado pelo mercado de trabalho, porém pouco reconhecido e valorizado.

O enfermeiro, no exercício da sua profissão, agindo de forma consciente do valor do seu papel, fundamental dentro dos serviços e instituições de saúde, em seus diferentes níveis, estará contribuindo para o processo de transformação de toda a categoria dentro do contexto político-social.
Desta forma, o objetivo desta pesquisa é identificar a produção literária acerca da formação do enfermeiro para a gestão em saúde.

\section{METODOLOGIA}

Trata-se de uma pesquisa bibliográfica narrativa, a fim de atender o objetivo proposto pela pesquisa.

A pesquisa bibliográfica permite "a cobertura de uma gama de fenômenos muito mais ampla do que aquela que poderia pesquisar diretamente". ${ }^{(12)}$ Este tipo de pesquisa, no entanto, não se refere a uma mera repetição do que foi publicado até o momento, visto que possibilita olhar sob outra perspectiva o mesmo assunto, gerando novas conclusões e demandas. ${ }^{(13)}$

Para a elaboração da pesquisa bibliográfica narrativa foram percorridas as seguintes fases: escoIha do tema; levantamento bibliográfico preliminar; formulação do problema; busca das fontes; leitura do material; fichamento; organização lógica do assunto e redação do texto. ${ }^{(14)}$

Para iniciar a busca bibliográfica, primeiramente delimitou-se a pergunta norteadora do estudo, que consiste em: Qual o panorama atual da formação do enfermeiro para a gestão em saúde, segundo a produção literária brasileira?

Para prover a seleção dos artigos utilizou-se a terminologia padronizada dos Descritores em Ciência da Saúde (DECS). Os descritores utilizados foram "Ensino", "Enfermagem", "Educação em Enfermagem", "Gestão em Saúde" e "Administração de Serviços de Saúde".

Os critérios de inclusão das produções científicas foram: ter sido publicado nos últimos treze anos (2000 a 2013) na língua portuguesa, relacionarem-se com o tema desta pesquisa e estar disponível gratuitamente, na íntegra, em formato eletrônico.

Os dados foram coletados por meio de levantamento da bibliografia publicada nas bases de dados SCIELO, LILACS, MEDLINE e Biblioteca digital de tese e dissertações da USP. 
Foram analisados os textos de forma seletiva e analítica, a fim de responder a questão de pesquisa levantada.

Na pesquisa bibliográfica através dos descritores supracitados, foram encontradas 466 publicações, sendo selecionados 68 artigos, através da leitura dos títulos e dos resumos, que mais se aproximavam da temática proposta no estudo.

Após a leitura na íntegra do material bibliográfico, foram analisados 35 artigos e or tese de doutorado.

O período do estudo teve duração de 06 (seis) meses, com ínicio no mês de junho e finalização no mês de novembro do ano de 2013.

\section{RESULTADOS E DISCUSSÃO}

A análise da produção científica estudada, composta por 35 artigos e a tese de doutorado elucidaram três categorias de análise, a saber: a formação do enfermeiro para a prática de gestão; a influência das exigências do mercado de trabalho na formação para a gestão e as competências para a formação no âmbito da gestão em saúde, discutidas a seguir.

\section{A FORMAÇÃO DO ENFERMEIRO PARA A PRÁTICA DE GESTÃO}

Esta categoria de análise, a partir dos estudos dos artigos, foi subdividida em: o ensino da enfermagem no Brasil e as suas diretrizes e avanços e desafios da formação.

\section{O ENSINO DA ENFERMAGEM NO BRASIL E AS SUAS DIRETRIZES}

Historicamente, a maioria das mudanças curriculares no ensino de enfermagem no Brasil denuncia a predominância do modelo médico/hospitalar no ensino de graduação, com base em evidências do tão antigo sistema nigthingaleano. A legislação sobre o ensino de Enfermagem no Brasil, desde a criação da escola Anna Nery, compreendendo os currículos de 1923, 1949, 1962 e 1972, revelam que a formação do enfermeiro era centrada no pólo individuo/doença/cura e na assistência hospitalar, seguindo o mercado de trabalho específico de cada época. E é nesse sistema nigthingaleano, criado por Florence Nigthingale no final do século XIX que a formação do enfermeiro passou a ser realizada com ênfase nas técnicas, em que a habilidade manual, a capacidade de memorização, a postura e a mecânica corporal no desenvolvimento das técnicas eram imprescindíveis, além do capricho, da organização e da perfeição. $(3,15,16)$

$\mathrm{Na}$ tentativa de modificar e atender as novas demandas do setor saúde no Brasil, que perpassarão por mudanças significativas, a exemplo da Reforma Sanitária, é que em dezembro de 1996, surge a Lei 9.394 - Lei de Diretrizes e Bases da Educação - LDB, a qual rege o Sistema Educacional Brasileiro. A LDB promove a descentralização e a autonomia das escolas e universidades, além de instituir um processo regular de avaliação do ensino. Para garantir as especificidades de cada curso na construção das Diretrizes Curriculares é estabelecido um conjunto de orientações, pareceres e resoluções onde é prevista uma reestruturação dos cursos de graduação, com a extinção dos currículos mínimos. $(5,15)$

O grande desafio na formação do enfermeiro é transpor o que é determinado pela nova LDB e pelas novas Diretrizes Curriculares ao formar profissionais que superem o domínio teórico prático exigido pelo mercado de trabalho, enquanto agentes inovadores e transformadores da realidade, inseridos e valorizados no mercado de trabalho. ${ }^{(15)}$

No ano de 2001, o Ministério da Educação MEC institui as Diretrizes Curriculares Nacionais do Curso de Graduação em Enfermagem, através da Resolução CNE/CES n ${ }^{\circ}$ 3, substituindo o conceito de "currículo mínimo" para as profissões superiores pelo conceito de "diretrizes curriculares". O documento que institui as diretrizes foi ou deveria ter sido construído em um processo colaborativo, 
desencadeado no ano de 1997, quando então o MEC provocou a discussão de sua construção..$^{(5,17)}$

As evidências e discussões dos artigos analisados neste estudo apontam outros caminhos no que tange as mudanças e inovações na formação dos enfermeiros. $O$ enfoque ainda concentra-se na área intra-hospitalar voltado para a prestação de cuidados em uma atuação assistencial, em detrimento a extra-hospitalar. ${ }^{(18)}$

Observa-se também, a existência de uma descontextualização em relação às realidades regionais $\mathrm{e}$ às práticas que realiza, desconsideração do trabalho como princípio pedagógico, contato tardio do aluno com a futura prática profissional, valorização do domínio de habilidades técnicas voltadas para um sistema de alta complexidade, reduzida ênfase no trabalho multiprofissional, currículos pouco flexíveis, dicotomia entre teoria/prática, pensar/fazer, cuidar/ administrar e a desarticulação da gerência com a assistência, o que não contribui para um exercício da profissão da enfermagem qualificada. $(6,9,18)$

É questão convergente nos resultados das pesquisas analisadas, a necessidade de melhorar o ensino de administração em enfermagem, tanto referente à carga horária, como à distribuição e aprofundamento de conteúdos, que dão ênfase à unidade hospitalar, ao modelo clínico individual; às teorias da administração; às propostas gerenciais prescritivas e normativas; à gestão da qualidade dos serviços; às características gerais das organizações, conforme as teorias científica, clássica e burocrática. ${ }^{(1,18)}$

Em uma pesquisa que analisou os planos de ensino de administração em enfermagem, em sua maioria, apontaram para planejamentos normativos e descompassados quanto à função administrativa do profissional no contexto do gerenciamento de serviços e de Recursos Humanos - RHs para o SUS. Mostraram-se incompletos porque são carentes de veiculação de conteúdos programáticos relativos às necessidades do SUS; inconvenientes porque, diante da possibilidade de escolha de um método compatível com a natureza e necessidade do conteúdo programático a serem repassados, os professores optam pela superposição de métodos e técnicas, obstaculizando o processo ensino-aprendizagem e dificultando o alcance dos objetivos inicialmente propostos; contraditórios porque suas abordagens pedagógicas, ao mesmo tempo em que são colocadas como problematizadoras, mostramse presas a alicerces tradicionais, desde o planejamento até a avaliação, passando pela fase de execução. ${ }^{(19,20)}$

Disso decorre a persistência da promoção de discussões mais aprofundadas acerca da possibilidade de implementação de processos de ensino transformadores, ancorados em bases conceituais, metodológicas e pedagógicas potentes, como orientadoras dos processos de formação. ${ }^{(19,20)}$

A formação não deve tomar como referência apenas a busca eficiente de evidências ao diagnóstico, cuidado e tratamento, mas também desenvolver condições de atendimento as necessidades de saúde das populações, da gestão macro e microssetorial, além de englobar aspectos de produção de subjetividade, habilidades técnicas e de pensamento e o adequado conhecimento do SUS. Decorre daí, a necessidade de se pensar a mudança nas instituições formadoras para que sejam dotadas de estruturas flexíveis, capazes de absorver conteúdos novos e integrarem-se em função dos verdadeiros problemas, o que implica uma significação mais ampla: a interação e o delineamento para o processo de transformação. ${ }^{(21,22)}$

A mudança de paradigma na atenção à saúde e, portanto, na formação desses profissionais envolve a formulação de novos modelos conceituais, a criação de novas instituições e a implementação de novas políticas. A formação de indivíduos críticos, questionadores e reflexivos com o desenvolvimento de habilidades, competências, atitudes e valores ético-políticos, é necessária para a mudança da atual situação da enfermagem, vislumbrando multidimensionalizar para pensar, tornando-o um formador de opiniões. ${ }^{(18,23,24)}$

$\mathrm{O}$ artigo 14 da Resolução CNE/CES n ${ }^{\circ}$ 03/2001 sugere a utilização de estratégias pedagógicas que articulem o saber; o saber fazer e o saber conviver, com vista a desenvolver o aprender a aprender, o aprender a ser, o aprender a fazer, o aprender a viver 
junto e o aprender a conhecer como atributos indispensáveis à formação do enfermeiro. ${ }^{(20,25)}$

Nesse contexto, é preciso considerar que "no processo pedagógico de formação profissional, a ponte entre a formação teórico-científica realizada intra muros e a realidade do meio, do mercado, é fundamental". Nessa perspectiva o desafio é tentar aproximar o conhecimento produzido na universidade articulado às mudanças que se processam na sociedade, especialmente no mundo do trabalho, para que na formação do enfermeiro sejam contemplados tanto os elementos particulares inerentes à profissão quanto os aspectos mais gerais do funcionamento da nossa sociedade. ${ }^{(26)}$

Portanto, a formação do enfermeiro, como visto e destacado em diversos estudos, ainda que tenham se modificado ou reconfigurado de acordo com as mudanças inerentes do processo de trabaIho do enfermeiro e as novas tendências educacionais, não comportam ou mesmo não contemplam parte da necessidade de se formar profissionais comprometidos e competentes para exercerem o trabalho em gestão de forma qualificada e segura.

É preciso que seja colocada, desde os componentes curriculares introdutórios, nos cursos de graduação em enfermagem, a administração/gestão em saúde, tanto nos seus aspectos técnico cientifico, quanto no seu aprofundamento junto à diversos outros componentes curriculares do cuidado, a exemplo.

Como forma de melhor embasamento e entendimento por parte dos alunos, da atividade cotidiana e rotineira do enfermeiro nos diversos serviços de saúde e ainda no que tange ao reconhecimento desse espaço, como sendo norteador do seu trabalho essencial, se faz necessário uma mudança conceitual, primordialmente, para orientar a construção de novos componentes curriculares na graduação.

\section{AVANÇOS E DESAFIOS DA FORMAÇÃO}

A formação dos enfermeiros, neste contexto de transformações por que passa o mundo e, especificamente, os serviços de saúde, vem sendo constantemente discutida, e tem apontado para a necessidade de mudanças. Como uma das estratégias, o ensino baseado em competências tem sido indicado nas Diretrizes Curriculares para os Cursos de Graduação em Enfermagem, atualmente em vigor. ${ }^{(27)}$

O Ministério da Saúde - MS, desde 2004, por meio da Secretaria de Gestão do Trabalho e Educação em Saúde - SGTES, desenvolve ações articuladas com o MEC, de modo a produzir propostas que sejam efetivas no campo da qualificação dos trabalhadores de saúde. Nessa perspectiva, o MS vem atuando com algumas estratégias e, dentre elas, duas se destacam: a primeira concerne a ressignificação dos projetos políticos pedagógicos - PPP dos cursos da área da saúde, para que as universidades do país possam formar profissionais capacitados para atuarem na construção de um novo modelo de atenção à saúde, projeto esse que vem sendo conhecido como Pró-Saúde.(3)

Alguns autores identificaram uma fragilidade no enfoque de aspectos políticos e sociais do gerenciamento na formação do enfermeiro. A necessidade de mudanças no sentido de promover estratégias de aproximação do processo ensino aprendizagem ao SUS, buscando, as universidades, parcerias nos serviços de saúde e nas organizações comunitárias, a fim de desenvolver o compromisso com a construção do saber para a melhoria de qualidade da vida e da saúde da comunidade. Nesse sentido, ocorreram avanços com a determinação da Lei Orgânica da Saúde de 1990, que, no artigo 6º inclui como campo de atuação do SUS "a ordenação da formação de recursos humanos na área da saúde" e "o incremento, em sua área de atuação, do desenvolvimento científico e tecnológico". Ainda que apenas sob forma de lei, a realidade do ensino de graduação em enfermagem, continua longe do ideal. $(8,21,28)$

Nessa direção, é necessário que o ensino esteja vinculado às demandas da comunidade, o que obriga as Instituições de Ensino Superior - IES a construírem ou repensarem seus Projetos Políticos Pedagógicos como processo permanente de dis- 
cussão das práticas, das preocupações e dos pressupostos da educação. Os egressos dos cursos de graduação em enfermagem enfrentam, no seu cotidiano de trabalho, situações complexas que os levam a confrontar as competências desenvolvidas durante o curso com as requeridas no exercício profissional. ${ }^{(1,29)}$

Outro ponto importante e indispensável na perspectiva de novos rumos para a formação está no trabalho em equipe e a inserção de todos os envolvidos com vistas à consecução de um trabalho mais articulado, integrado e qualificado. As práticas pedagógicas devem ser remodeladas para que a fragmentação seja substituída pela integralidade nos diversos processos de ensino, no sentido de fortalecer a interdisciplinaridade. ${ }^{(1,8,21)}$

A interdisciplinaridade rompe com a dominação dos especialistas e incute uma visão não fragmentada da saúde, estimulando a integração e o diálogo dos diversos saberes, bem como a intersetorialidade, a qual exige um processo sistemático de articulação, planejamento e coordenação entre os diferentes setores da sociedade.

A capacidade de articular esses conhecimentos profissionais específicos com os de toda a rede de saberes envolvidos no sistema de saúde, por meio de ação dialógica com diferentes atores sociais, leva ao enfrentamento dos problemas de saúde e a melhoria nas condições de vida.

Os desafios propostos pelo sistema de saúde do Brasil trazem as necessidades de qualificação profissional, o que inclui o conhecimento das políticas públicas, dos modos de operar novos dispositivos de cuidado a saúde, rede de serviços articuladas e acolhedoras, dentre outras. ${ }^{(21,30)}$

As instituições devem garantir a autonomia de todos os profissionais e, simultaneamente, co-responsabilizar todos os envolvidos no processo. ${ }^{(8)} \mathrm{O}$ desafio dos docentes reverem seus conceitos e métodos é reconhecido, inclusive por meio de um processo de mudança voltado a estruturas de ensino que posicionem o aluno como protagonista de sua aprendizagem e facilite a apreensão de conhecimentos, habilidades e atitudes durante a formação para a posterior mobilização de competências em sua prática profissional.(4)

A falta de autonomia do aluno interfere negativamente na formação, que se agrava devido à conduta de alguns professores, que restringem as oportunidades da prática no Ensino Clínico a cuidados básicos em detrimento de outras práticas, consideradas essenciais à formação do enfermeiro. ${ }^{(1)}$

Os estudos mostram ser tarefa do educador apontar caminhos para uma prática de saúde cidadã assim como é através de uma relação dialógica com os alunos, que se pode ajudá-los a construir os seus projetos profissionais. O sentido será sempre levar a discussão/reflexão e posterior aprofundamento com leituras complementares, a fim de que o aluno assuma a responsabilidade pelo seu aprendizado. Esta se fará de forma a reforçar nos alunos a ideia do compromisso com o aprender, possibilitar o diagnóstico e acompanhamento da aprendizagem e, quando necessária, a sua reorganização para superar possíveis dificuldades e estimular cada aluno a construir seu saber, possibilitando-o o alcance de uma visão mais integral acerca do processo saúde doença e consequentemente um agente de transformação social. ${ }^{(28)}$

Em contrapartida, o modelo do ensino tradicional, coloca um desafio inerente e de difícil mudança quando assume a educação/formação centrada no professor, detentor do conhecimento, e na transmissão dos conteúdos para memorização. O professor assume funções de como vigiar e aconselhar os alunos, corrigir e ensinar a matéria. É visto como autoridade máxima, um organizador dos conteúdos e estratégias de ensino e, portanto, o único responsável e condutor do processo educativo. ${ }^{(21)}$ Os conteúdos programáticos, embora obedeçam a certo padrão sequencial, se mostram diferentemente contextualizados, a partir da visão de mundo de cada professor entrevistado. ${ }^{(20)}$

A atual pedagogia da transmissão, parte da premissa de que o conhecimento e as ideias são os pontos mais importantes da educação, logo o estudante é visto como uma página em branco. Quanto às relações estabelecidas entre os agentes 
envolvidos no processo educativo, sejam eles educador e educando ou professor e estudante, este ocupa um papel de agente passivo e ignorante e o professor seria aquele que detém todo o conhecimento. ${ }^{(5)}$

Para avançar e transformar a realidade tangente, alguns possíveis fatores dificultadores precisam ser ultrapassados como o despreparo do corpo docente, os currículos ultrapassados nos quais o ciclo básico e o ciclo clínico não se relacionam, a excessiva carga horária, a dissociação entre teoria e prática e a ênfase na assistência especializada e no uso maciço da tecnologia. Deve-se, portanto buscar a adoção de instrumentos diversificados, com o entendimento que o conjunto de saberes e fazeres é que consolidará a almejada identidade profissional dos enfermeiros. ${ }^{(5,18)}$

Nos estudos analisados, observou-se que o conteúdo prático de administração é ministrado de forma concentrada nos últimos semestres do curso, dificultando a sedimentação e a apropriação desse conhecimento pelos alunos. Parece ser reforçada na escola a percepção de que os processos de cuidar e administrar quase não se tocam, uma vez que primeiro o aluno aprende a cuidar do cliente e depois a gerenciar a assistência. Os estudantes percebem a fragmentação do conhecimento tanto nos diversos processos de ensino quanto na pratica das atividades de enfermagem para a gestão, já que a prática, a problematização dos conteúdos e a vivência dos serviços de saúde acontecem em períodos diferentes. ${ }^{(19,21)}$

O processo de ensino das disciplinas relacionadas à administração encontra-se em descompasso com os requerimentos da práxis profissional prevista para os enfermeiros, enquanto administradores de recursos humanos e serviços de saúde, em consonância com a política de saúde vigente no país. Nesse sentido, os estudos consideram que o ensino da administração em enfermagem deve ser um dos eixos horizontais na grade curricular. ${ }^{(18,20)}$
$\mathrm{Na}$ busca por suprir e redefinir as lacunas existentes no ensino de graduação, o Curso de Ativadores de Mudança na Formação Superior de Profissionais de Saúde é um dos cursos da Coordenação da EAD/Ensp, no âmbito do Sistema Universidade Aberta do Brasil - UAB/Capes. Contribui substancialmente, por meio dos conhecimentos atualizados oferecidos, além de oportunizar vivências metodológicas de ensino diferentes das formas tradicionais, provocando reflexões e possibilitando aplicações em nosso cotidiano, uma vez que metodologias pedagógicas ativas propiciam a formação de sujeitos mais críticos, reflexivos e participativos, com competências e habilidades para influir e tentar mudar a realidade social. ${ }^{(28)}$

Entende-se como prioridade, a busca pelo enfrentamento e superação do atual modelo de ensino-aprendizagem nas Escolas de Enfermagem, sendo necessária a construção de um novo olhar sobre pensar e fazer saúde, a fim de que o comprometimento social e o exercício da cidadania sejam elementos transversais em todo o currículo. De forma direta, é que esses elementos influenciam positivamente na prática da gestão, conformando um profissional capaz de intervir e modificar a realidade existente nos serviços e instâncias de saúde.

$O$ aprendiz deve refletir criticamente sobre todo o processo de formação, enquanto sujeito ativo e consciente, levando-os a serem os agentes de mudanças da sua trajetória profissional. Nesse sentido, devem ser estimulados e fomentados, ainda na graduação, a análise e reflexão do papel e das atribuições do enfermeiro, segundo a história da profissão.

Importantes avanços ocorreram, apesar de obstáculos ainda existirem, na formação do enfermeiro, que atualmente caminha para uma nova perspectiva, sendo ela ainda pouco estudada e discutida, mas dando indícios de que a velha concepção técnica assistencial do enfermeiro está sendo substituída por componentes éticos, políticos, sociais e desenvolvimento de competências. 


\section{A INFLUÊNCIA DAS EXIGÊNCIAS DO MERCADO DE TRABALHO NA FORMAÇÃO PARA A GESTÃO}

A expansão dos cursos universitários representa democratização do acesso ao ensino superior e maior disponibilidade de profissionais no mercado de trabalho. Observa-se que a partir de 1995 existiu um aumento da procura pelos cursos de Graduação em Enfermagem e posteriormente para suprir essa demanda a ocorreu a ampliação de vagas para responder a essa procura. Este aumento pode estar relacionado a implementação do SUS, com crescimento de postos de trabalho e a implantação do PSF, que se tornou uma interessante área para atuação dos enfermeiros. ${ }^{\left({ }^{11}, 32\right)}$

A quantidade de postos de trabalho existentes não é suficiente para absorver o crescente número de profissionais disponíveis nos vínculos dos estabelecimentos de saúde e nos empregos formais, acarretado um excedente de enfermeiros formados. Essa realidade reflete numa tendência de desemprego crescente, levando ao profissional a submeter e aceitar qualquer emprego, em condições impostas pelo mercado, transformando os vínculos de trabalho levando a informalidade e a precárias e vergonhosas condições de trabalho, desregulamentação da carga horária e de pisos salariais ou até mesmo ao abandono da profissão. Transformações que podem produzir um efeito negativo na procura pelo curso, o que influencia a graduação a uma lógica mercadológica do ensino. (31)

De acordo com a história, o que se buscou ensinar nas escolas de enfermagem foi regularizado e direcionado em adaptação às exigências do mercado. Esses ajustes não foram satisfatórios para dar à enfermagem respaldo para superar essas cobranças. Pelo contrário, só tornou a enfermagem mais presa, aceitando passivamente o autoritarismo das políticas centrais, seja elas posta para a saúde ou somente para a educação. ${ }^{(33)}$

O perfil exigido para o gestor da atualidade sofreu mudanças no mercado de trabalho, necessita-se de profissionais com requisitos imprescindíveis que possam suprir com rapidez as necessidades e adaptarem-se as novas situações, ser flexível e ter a capacidade de relacionar-se de assumir desafios. ${ }^{(27)}$

Como pré-requisitos gerais, o enfermeiro deve ter disposição pessoal, autocontrole e estabilidade emocional, capacidade física e mental para exercer a profissão, acondicionamento para cumprir ações, competência para trabalhar em equipe, facilidade de comunicação, iniciativa e estar apto para a capacitação recorrente e também capaz para realizar ações específicas de enfermagem, devendo além das ações assistenciais, oferecer serviços operacionais, administrativos e gerenciais. ${ }^{(8,18)}$

Além de o enfermeiro atuar no cuidado direto ao paciente deve ainda, envolver-se com práticas sociais da sua instituição, motivar, valorizar e facilitar tanto os seus resultados de trabalho quanto os da equipe, ser ético, empreendedor e buscar o domínio das técnicas de gestão. Sendo que um gestor competente é aquele que procura a humanização do trabalho por intercessão de uma gestão democrática, flexível e de programas de valorização pessoal do seu grupo, ponderando os resultados como um trabalho em conjunto e tem o compromisso de atuar em benefício de transformações e ter cobiça para buscá-las, mesmo diante de adversidades. ${ }^{(3,8)}$

O gestor deve fazer uso de tecnologias leves e avaliar os profissionais de saúde e os usuários como pesas chaves para a produção das ações de saúde, inclusive compreendendo-os como co-responsáveis do trabalho em saúde. O gestor também deve ser competente para arranjar concordâncias e alianças socialmente construídas, se contestando à racionalidade gerencial burocratizada, normativa e tradicional. Também se faz indispensável que o gestor verdadeiramente, conheça a realidade de seu território, para que ele possa desenvolver as ações gerenciais que venham a contemplar os princípios do SUS. Ele de conhecer, para nortear as suas práticas, o conceito ampliado de saúde e que este seja compreendido como sinônimo de qualidade de vida, tendo como objetivos a prevenção 
e a promoção da saúde da população sob sua responsabilidade. ${ }^{(3,34)}$

As instituições de ensino sempre tentam se adequar às necessidades do mercado e, constituindo uma das preocupações para as mudanças curriculares no ensino de enfermagem, por outro, o mercado sempre esta insatisfeito com as mudanças realizadas no currículo propostas para subsidiar as exigências. Fica um pouco difícil compreender esse desacerto. Existindo aí a dissociação entre o que se é visto na teoria e o que se realmente se quer na prática. É importante ponderar formas de reorganizar o sistema de ensino, educando profissionais com perfis adaptados às exigências no mundo moderno e do futuro de incerto, capazes de refletir com criatividade e que possam encarar mudanças profissionais. ${ }^{(15,35)}$

As diferenças de visão entre a academia e as exigências do mercado são confirmadas por alguns egressos que evidenciam a não articulação dos conteúdos ministrados apesar destes serem organizados de forma sequencial e em níveis de complexidade e nem mesmos conhecimentos teórico práticos. Tendo que ocorrer a evoluir e se alinhar a graduação para que possa acompanhar as novas demandas gerenciais do sistema. ${ }^{(19,23)} \mathrm{O}$ mercado de trabalho neste novo milênio necessita de profissionais redimensionados, multidisciplinares, polivalentes, mas também capazes de assumir compromisso de cuidar e que definam seu espaço social.(33)

A formação para gestão vem tentando se readequar para suprir às novas exigências necessárias a um bom perfil profissional, que precisa ser bem mais capacitado, competente, com postura ética e moral e que possua um vasto leque de atributos que possam contribuir com a instituição. Com as transformações rápidas do mercado de trabalho, o grande desafio hoje, é atrair e reter pessoas talentosas, que detêm conhecimento e agreguem valores com suas potencialidades, habilidades e saberes, em um contexto muito mais seletivo, devido ao crescente número de enfermeiros disponíveis e o decréscimo no nível de ensino superior da enfermagem.
Para a formação de futuros gestores capacitados ao mercado seria necessário a adequação entre a teoria, prática e articulação de conteúdos com o mundo do trabalho. Mas também dessa forma os profissionais teriam um enfoque exclusivamente mercadológico, visando àquilo que instituição almeja, esquecendo-se do seu crescimento pessoal, tornando-se um profissional despreparado para as mudanças que possam ocorrer no futuro. É necessário que esse gestor venha a ter uma visão mais ampla da sua profissão, para que com o conhecimento amplificado possa ter a capacidade de inovar, buscar novos horizontes, novas oportunidades e possibilidades, beneficiando não somente o local de trabalho, à equipe, à instituição, mas também a si e a toda a sociedade.

\section{AS COMPETÊNCIAS PARA A FORMAÇÃO NO ÂMBITO DA GESTÃO EM SAÚDE}

O desenvolvimento de competências para a atuação no âmbito da gestão em saúde pelo enfermeiro passa a ter uma grande valorização, devido ao crescente aumento da competitividade no mercado de trabalho e na economia. As organizações e empresas buscam, atualmente, nos profissionais competências anteriormente negligenciadas, quando a concorrência era menor e seus funcionários pouco controlados em relação a sua qualificação, capacitação e desempenho profissional. Gerando uma acomodação por parte dos trabalhadores na procura de um desenvolvimento pessoal e técnico. $\left.{ }^{33}, 36\right)$

Essa realidade reflete nas entidades de ensino que tiveram que adequar a formação dos profissionais da saúde, implantando o desenvolvimento de competências traduzidas em conhecimento, habilidades e atitudes, que irão possibilitar a preparação das pessoas para uma atuação profissional ou para qualquer conduta em situações de vida social. Ou seja, prepara-los para que sejam competentes. $(33,37)$

As exigências crescentes de produtividade e de qualidade e um contexto de mercado de trabalho 
instável e flexível ampliam os requisitos de qualificação dos trabalhadores e tornam cada vez mais generalizada a implantação de modelos de formação e de gestão baseados em competências profissionais. ${ }^{(8)}$

A formação do enfermeiro pautada no desenvolvimento de competências é um grande desafio e necessita de esclarecimento e discussões sobre quais as competências que a graduação realmente oferece, quais as que o mercado de trabalho desejo e quais são realmente necessários para qualificar e subsidiar os profissionais nas suas praticas cotidianas. ${ }^{(18,37)}$

O conceito de competência, adotado segundo um estudo sobre a mudança no currículo da formação, mostra como sendo a capacidade para enfrentar varias situações equivalentes, motivando de forma correta, eficaz, coerente e criativa vários recursos cognitivos: saberes, capacidades, microcompetências, informações, valores, atitudes, esquemas de percepção, de avaliação e de raciocínio. (28)

As competências não é algo incorporado de uma só vez é construído cotidianamente. Faz parte do envolvimento do profissional na formação e avaliação dos seus saberes, que deverão estar em constante construção como uma meta de excelência a ser alcançada. ${ }^{(9,28)}$

Dentre as competências gerais, determinadas pelas DCNs dos cursos de Enfermagem, está a aptidão desses profissionais para a realização da gestão/gerência da força de trabalho, dos recursos materiais e físicos, a liderança, assim como o empreendedorismo. É nesse sentido que a capacidade/habilidade técnico-científico, ético-político e sócioeducativo dos enfermeiros, os permitam serem reconhecidos como coordenadores líderes da equipe de enfermagem, a fim de atuarem em atividades de política e planejamento em saúde e gerenciar o processo de trabalho em enfermagem com princípios éticos e humanísticos, com resolutividade, tanto em nível individual como coletivo, em todos os âmbitos da saúde. . 9,38$)^{2}$

Dentre os cursos de saúde, a enfermagem é a que mais aborda e trabalha com temas como liderança, planejamento, coordenação de equipe e serviços. Este preparo é denotado no mercado de trabalho, onde existe um grande número de enfermeiros ocupando cargos de gerencia e chefia de equipes. $O$ enfermeiro possui um perfil gerencial delineado pelo sua formação suas características qualidades profissionais e pessoas e seu grau de conhecimento técnico. $.5,9,39)$

O ensino por competências das instituições de formação procura que o profissional egresso venha a possuir a capacidade de utilizar de forma correta uma variedade de conhecimentos para solucionar problemas do cotidiano. No âmbito gerencial as transformações ocorridas na sociedade levam a utilização de novas abordagens gerencias e novas alternativas de organização do trabalho. O que impressiona ao aprendizado de novas abordagens e flexibilidade, redução da hierarquia trabalho em descentralização e equipe das decisões visando a satisfação de todos. ${ }^{(8)}$

O desenvolvimento dessas competências e habilidades deve acontecer em conjunto com os projetos politico pedagógicas das instituições de ensino que devem destacar nos seus planos de ensino enfatizando os temas administrativos também de forma politica e teórica buscando aproximar à formação dos profissionais a realidade dos serviços de saúde $(6,18,38)$.

Para que o ensino superior seja efetivo deve-se existir o entrelaçamento de vários fatores estruturadores da formação os formados pela instituição a docência, o currículo e os alunos e as politicas de educação superior os avanços da ciência, pesquisa e cultura e também as exigências do mercado de trabalho. ${ }^{(1,30)}$

Num ambiente globalizado faz-se necessaro que o enfermeiro amplie e busque ter varias competências além de habilidades tecnicas, pois somente estas não são suficinetes para uma boa qualificação do trabalho gerencial em saúde. ${ }^{(23)}$

A educação superior tem a responsabilidade e o compromisso de realizar a formação de profissionais críticos, competentes, reflexivos e cidadãos que tenham a capacidade de atuar não somente em sua área de formação, mas também no processo de transformação da sociedade. ${ }^{(15,17)}$ 
Administrar organizações de saúde requer do enfermeiro competências especificas, traduzidas em seus conhecimentos habilidades e atitudes, capacidade de analise situacional, tomada de decisões, apresentar soluções e resolver problemas, propiciar inovação, administrar conflitos, vivenciar várias mudanças das dinâmicas de organizacionais. Por isso se faz necessário que órgãos formadores acompanhem essas mudanças vivenciadas no setor saúde e incorpora-las a suas bases de ensino, competências e habilidades administrativas e de gestão que colaborem para o cotidiano de trabalho. ${ }^{(4,6)}$

As novas alternativas de formação dos profissionais de saúde que se fazem necessárias para um novo desempenho torna-se motivo de preocupação tanto para os formandos como para os estudantes que solicitam mudanças no modelo de ensino de informação e habilidades que é tradicional unidirecional e fragmentado para que seja substituído pela educação permanente e o auto aprendizado, buscando continuamente conhecimentos para sustentarem cientificamente sua atuação como gestores do processo de trabalho. Formando um indivíduo critico e reflexivo na sua prática cotidiana e também estimular e incentivar o desenvolvimento do perfil gerencial do enfermeiro. ${ }^{(21,40)}$

É necessário a procura do desenvolvimento de competências e saberes individuais ao gestor como persuasão, liderança, trabalhar em equipe, tomada de decisão, planejamento e organização e determinação, articulação, enfrentamento de problemas, postura ético moral, autonomia iniciativa, sensibilidade, capacidade de se relacionar consigo mesmo e com os outros, capacidade de coordenação de grupos. As competências também são assim elencadas: saber ser, saber agir e reagir com competência, saber combinar recursos e mobiliza -los no contexto saber transpor, comunicar, aprender a aprender e envolver-se, compreender-se, ser estratégico e ser responsável. ${ }^{(18,27)}$

Para tratar de obter além de conhecimentos e a produção de habilidades técnicas deve-se ocorrer uma nova orientação do modelo educacional em enfermagem. Assim tornando-se fundamental a aquisição de habilidades sociais e nação critica e ética, que possam alavancar a ruptura com atuais padrões de gestão. ${ }^{(15)}$

O perfil de enfermagem requerida na atualidade necessita da junção entre gerenciar e cuidar, assim como o gerenciamento não somente realizado de forma lógica, mecânica e burocrática. Sendo indispensável que haja nexo entre a sua trajetória acadêmica o mundo do trabalho e a sua carreira profissional, para que assim o enfermeiro realize a assistência e os processos gerenciais de forma completa na sua rotina de trabalho. Tornando-se um profissional inovador e modificador da realidade.(1)

Existem grupos de competências que o estudante deve englobar em seus atributos como gestor: aqueles exigidos pelo mercado, os que a graduação oferece e os que realmente são fundamentais para sua carreira. Esses grupos devem ser abordados não de forma separada, mas entrelaçados, para que assim, haja a possibilidade de tornar o estudante completo e preparado para a sua construção tanto como sujeito, tanto como profissional.

Com as transformações ocorridas no mercado, cada vez mais competitivo, são exigidas do gestor múltiplas competências para que este possa realizar seu trabalho em nível de excelência. E para que isso possa ocorrer, é preciso uma renovação de conhecimentos constantes, acompanhando as necessidades do mundo moderno cheio de tecnologias e possibilidades e também muito envolvimento pessoal do gestor em seu desenvolvimento contínuo.

As instituições de ensino também precisam atualiza-se e caminhar junto com as inovações, para formar profissionais preparados para o desempenho de sua função de forma qualificada, capacitados para solucionar, transformar ou inovar qualquer situação.

\section{CONCLUSÃO}

Esta pesquisa teve por objetivo identificar a produção literária acerca da formação do enfermeiro para a gestão em saúde, possibilitando ao leitor 
uma reflexão sobre o panorama geral brasileiro do ensino de graduação em enfermagem para a gestão em saúde, segundo o olhar de diversos autores e dos resultados dos estudos analisados.

Para o alcance do objetivo proposto, buscou-se tomar conhecimento, desde a origem, sobre o ensino e suas diretrizes, elencar os avanços e desafios existentes na formação, assim como, propor um aprofundamento diante da temática gestão em saúde, introduzindo o entendimento sobre as influências do mercado de trabalho na formação e as competências necessárias e específicas para o trabalho do gestor.

Evidenciou-se à luz do referencial teórico que o processo de formação do enfermeiro para a gestão em saúde, deve contemplar a busca pela qualificação, através da capacitação, valorização, empoderamento e eficiência/eficácia na tomada de decisões, ação essa, mais que conhecida pelos enfermeiros, seja no que tange ao cuidado direto ao usuário, seja em sua função gerencial mais primordial.

Nesse sentido, é que as mudanças devem se aproximar, pois a realidade posta nas instituições de ensino superior (IES), de acordo com os diversos estudos que compõe esta pesquisa, ainda não se firmou para uma prática de ensino que contemple e aprimore a intrínseca relação do gerenciar e cuidar, formando profissionais competentes e potentes para atuarem na gestão do cuidado, de forma ética, humanística e crítica, alinhado com as demandas do mercado de trabalho.

Partindo desse contexto, ressalta-se a necessidade de mudanças nos projetos políticos pedagógicos dos cursos de graduação em enfermagem, a fim de tomar a gestão em saúde, eixo transversal nos diversos componentes curriculares.

Entre os estudos pesquisados sobre a formação do enfermeiro para o trabalho em gestão em saúde, denota-se um distanciamento entre o ensino e a prática profissional cotidiana e a origem histórica da profissão. Tal formação está voltada para o tecnicismo e o assistencialismo na prestação do cui- dado direto com o paciente, de forma conflitante com as exigências do mundo do trabalho.

As diversas e complexas atribuições do enfermeiro, o colocam como peça chave nos serviços de saúde, devendo, portanto, obter conhecimentos específicos, científicos, técnicos, políticos e de gestão que o façam caminhar rumo a uma mudança na realidade dos diversos níveis de atenção a saúde.

Recomenda-se a partir dessa pesquisa, a continuidade do estudo de forma aprofundada sobre a temática. Sugere-se também, a maior divulgação de fóruns de debates sobre o tema, incluindo todo o segmento educacional da área de enfermagem, criando assim, um ambiente propício a desenvolver ações estratégicas para a melhoria da qualificação do ensino de enfermagem no Brasil.

\section{REFERÊNCIAS}

1. Montezeli JH, Peres AM. Gerenciamento: contrapontos percebidos por enfermeiros entre a formação e o mundo do trabalho. Ciênc. cuid. Saúde. 2012;11(supl) :138- 43.

2. Morais VR. A especificidade do trabalho da enfermeira na atenção hospitalar [dissertação]. Salvador (BA): Universidade Federal da Bahia, 2011.

3. Meira MDD, Kurcgant P. Avaliação da formação de enfermeiros segundo a percepção de egressos. Acta paul. enferm. 2008; 21(4)556-61.

4. Xavier GLM, Barbosa TLA. Trabalho das enfermeiras-gerentes e a sua formação profissional. Trab. educ. saúde. 2011;9(3):449-59.

5. Silva JC, Rozendo CA, Brito FMM, Costa TJG. A percepção do formando de enfermagem sobre a função gerencial do enfermeiro. Rev. Eletr. Enf. 2012;14(2):296-303.

6. Martins VA, Nakao JRS, Fávero N. Atuação gerencial do enfermeiro na perspectiva dos recém-egressos do curso de enfermagem. Esc. Anna Nery. 2006;10(1):101-8.

7. Brasil. Ministério da Educação e Cultura. Secretaria do Ensino Superior. Diretrizes 
curriculares nacionais para a área da saúde. Brasília (DF): MS;2OOl.

8. Barrêto AJR, Sá LD, Silva CC, Santos SR, Brandão GCG. Experiências dos enfermeiros com o trabalho de gestão em saúde no estado da Paraíba. Texto contexto enferm. 2010;19(2):300-8.

9. Worschech GJM. Formação do enfermeiro: buracos negros e pontos de luz [tese]. Ribeirão Preto (SP): Universidade de São Paulo, 2004.

10. Brasil. Ministério da Saúde. Secretaria de Políticas de Saúde. Gestão Municipal de Saúde: textos básicos [Internet]. Rio de Janeiro (RJ): 2001; 344p. [acesso em 12 de abr de 2013]. Disponível em: http://portal.saude.gov.br/portal/ arquivos/pdf/gestao_municipal_de_saude.pdf

11. Fernandes MC, et al. Análise da Atuação do Enfermeiro na Gerência de Unidades Básicas de Saúde. Rev. bras. Enferm. 2010;63(1).

12. Gil AC. Métodos e técnicas de pesquisa social. $5^{a}$ ed. São Paulo: Atlas, 1999.

13. Marconi MA, Lakatos EM. Técnicas de pesquisa. $5^{\mathrm{a}}$ ed. São Paulo: Atlas, 2002.

14. Gil AC. Como elaborar projetos de pesquisa. $4^{\mathrm{a} e d .}$ São Paulo: Atlas, 2002.

15. Faustino RLH, Moraes MJB, Oliveira MAC, Egry EY. Caminhos da formação de enfermagem: continuidade ou ruptura? Rev. bras. Enferm. 2003;56 (4):343-47.

16. Formiga JMM, Germano RM. Por dentro da história: o ensino de Administração em Enfermagem. Rev. bras. Enferm. 2005;58(2):222-26.

17. Haddad AE. A enfermagem e a política nacional de formação dos profissionais de saúde para o SUS. Rev. esc. enferm. USP. 2011;45(spe2) :18039.

18. Dias DC, Murofuse NT, Schneide JF, Tonini NS, Oliveira BRG. Reflexões sobre o desafio da administração da educação em enfermagem. Rev. bras. enferm. 2004;57(4): 490-2.

19. Aarestrup C, Tavares CMM. A formação do enfermeiro e a gestão do sistema de saúde. Rev. Eletrônica de Enferm. 2008;10(1):228-34.

20. Montezeli JH, Peres AM. Competência gerencial do enfermeiro: conhecimento publicado em periódicos brasileiros. Cogitare enferm. 2009;14(3).

21. Almeida ML, Peres AM. Conhecimentos, habilidades e atitudes sobre a gestão dos formados de enfermagem de uma universidade pública brasileira. Invest Educ Enferm. 2012;30 (1).

22. Pires MRGM, Spagnol CA, Brito MJM, Gazzinelli MFC, Montenegro LC.

23. Diálogos entre a arte e a educação: uma experiência no ensino da disciplina de administração em saúde. Texto contexto enferm. 2009;18 (3):559-67.

24. Celento DD, Tavares CMM. Avaliação dos estudantes de enfermagem sobre o ensino da gestão do sistema de saúde. Rev. min. Enferm. 2012;16(3):355-63.

25. Bonetti OP, Kruse MHL. A formação que temos e a que queremos: um olhar sobre os discursos. Rev. bras. enferm. 2004;57(3):371-9.

26. Villas Bôas LMFM, Araújo MBS, Timóteo RPS. A prática gerencial do enfermeiro no PSF na perspectiva da sua ação pedagógica educativa: uma breve reflexão. Ciênc. saúde coletiva. 2008;13(4):1355-60.

27. Bueno AA, Bernardes A. Percepção da equipe de enfermagem de um serviço de atendimento pré-hospitalar móvel sobre o gerenciamento de enfermagem. Texto contextoenferm. 2010;19(1):45-53.

28. Farias LD, Silva CC. Administração em enfermagem: desvelando as bases conceituais, metodológicas e pedagógicas de seu ensino em joão pessoa - PB. Ciênc. cuid. Saúde. 2008;7(1):37-44.

29. Santos AMR, Reichert APS, Nunes BMVT, Morais SCR, Vasconcelos OADS, Magalhães RLB. Construção coletiva de mudança no Curso de Graduação em Enfermagem: um desafio. Rev. bras. enferm. 2007;60(4):410-15.

30. Rodrigues RM, Caldeira S. Formação na graduação em Enfermagem no estado do Paraná. Rev. bras. Enferm. 2009;62(3).

31. Silva KL, Sena RR, Seixas CT, Silva MEO, Freire LAM. Desafios da política, da gestão e da assistência para a Promoção da saúde no 
cotidiano dos serviços. REME - Rev. Min. Enferm. 2012;16(2):178-87.

32. Silva Kênia Lara, Sena Roseni Rosângela de, Tavares Tatiana Silva, Wan der Maas Lucas. Expansão dos cursos de Graduação em Enfermagem e mercado de trabalho: reproduzindo desigualdades?. Rev. bras. enferm. 2012 June;65( 3 ):4O6-13.

33. Jesus BH, Gomes DC, Spillere LBB, Prado ML, Canever BP. Inserção no mercado de trabalho: trajetória de egressos de um curso de graduação em enfermagem. Esc. Anna Nery. 2013;17(2):336-45.

34. Ito EE, Peres AM, Takahashi RT, Leite MMJ. $O$ ensino de enfermagem e as diretrizes curriculares nacionais: utopia $\times$ realidade. Rev. esc. enferm. USP. 2006;4O(4):570-5.

35. Lourenção DCA, Benito GAV. Competências gerenciais na formação do enfermeiro. Rev. bras. enferm. 2010; 63(1):91-7.

36. Mattosinho MMS, Coelho MS, Meirelles BHS, Souza SS, Argenta CE. Mundo do trabalho: alguns aspectos vivenciados pelos profissionais recém- formados em enfermagem. Acta paul. enferm. 2010; 23(4):466-71.

37. Cunha ICKO, Ximenes NFRG.

Competências gerenciais de enfermeiras: um novo velho desafio?. Texto contexto enferm. 2006;15(3):479-82.

38. Ciampone MHT, Kurcgant P. O ensino de administração em enfermagem no brasil: o processo de construção de competências gerenciais. Rev. bras. enferm. 2004; 57(4):401-7.

39. Brasil. Ministério da Saúde. Secretaria do Ensino Superior. Resolução CNE/CES N 3, de 7 de novembro de 2001. Brasília (DF): MS; 2001.

4O. Paim JS. Epidemiologia e planejamento: a recomposição das práticas epidemiológicas na gestão do SUS. Ciênc. saúde coletiva. 2003;8(2):557-67.

41. Camelo SHH, Angerami ELS. Competência profissional: a construção de conceitos, estratégias desenvolvidas pelos serviços de saúde e implicações para a enfermagem. Texto contexto - enferm. 2013;22(2):552-60. 